\title{
Removal of heavy metal ions from industrial wastewater using magnetic nanoparticles
}

\author{
K. Anbalagan*, M. Magesh Kumar*, J. S. Sudarsan** and S. Nithiyanantham*** \\ * Department of Chemical Engineering, SRMIST, Kanchipuram Dt., Kattankulathur-Tamil Nadu, India \\ ** School of Construction Management (SOCM), NICMAR Pune, Balewadi, Pune, India \\ *** Post Graduate and Research Department of Physics, Thiru.Vi.Kalyanasundaram Govt Arts \& Science College, Thiruvarur, Tamilnadu, \\ India \\ ***Corresponding Author: s_nithu59@rediffmail.com
}

Submitted :06/09/2020

Revised : 19/08/2021

Accepted :29/08/2021

\begin{abstract}
In this work, maghemite $\left(\gamma-\mathrm{Fe}_{2} \mathrm{O}_{3}\right)$ and magnetite $\left(\mathrm{Fe}_{3} \mathrm{O}_{4}\right)$ nanoparticles were synthesized using coprecipitation method, and characterization was done using X-ray diffraction (XRD), scanning electron microscopy (SEM), energy dispersive spectroscopy (EDS), and Fourier transform infra-red spectroscopy (FTIR). The size of these particles was found to be in the range from 20 to $100 \mathrm{~nm}$, and these particles were used as nanoadsorbents for the removal of heavy metal ions like chromium and copper from the artificial wastewater. Adsorption depends on the optimum conditions of parameters such as $\mathrm{pH}$ (2.5 and 6.5), contact time (60 and 80 minutes), and dosages at room temperature for chromium and copper that were observed with a removal efficiency of $92 \%$. These particles showed remarkable efficiency in removal of metals. Further, these particles were regenerated for reuse, and desorption was done using $\mathrm{HCl}$ and $\mathrm{NaOH}$ effluent for copper and chromium metals, respectively. The removals of pollutant enhanced with magnetic nanoparticles are evident with the obtained results. The separation factor $(\mathrm{r})$ lies between 0 and 1 , indicating favoring Langmuir isotherm for both chromium and copper ions.
\end{abstract}

Keywords: Magnetism; Nanoparticle; Isotherm; Pollutant; Wastewater.

\section{INTRODUCTION}

Water is one of the basic necessities of man, and with the industrial revolution, most of the industrial wastes flowed to the nearby water reservoirs, causing harmful effect on environment. Industrial waste waters mainly contain heavy metals like chromium, copper, arsenic, cadmium, zinc, lead, and nickel, which are toxic and carcinogenic. So, it has become a necessity for the removal of heavy metals from the industrial wastewater [1- 4].

Chromium and its related metals are used in many industries. The effluents from the industries are having chromium ions and many other harmful unwanted chemicals. The presence of chromium more than optimum in effluents is harmful, causing several issues such as indigestion, ulcer, skin allergy, and liver damage. In order to avoid the various harmful metal ions causing diseases for human, the removal of pollutants with proper technique to adsorb harmful metal ions of wastewater of effluents from the industries is necessary [5-10]. Cu2+ ions are among the major pollutants, and they cause hemolysis, diarrhea, kidney failure, improper respiration, and etc. The pollutants are 
majorly from industries such as dye, paper, refinery, and plating [11-16]. There is a demand for the method of removal of pollutants to be environmentally free and cost effective; it may be applicable to developing and undeveloped countries worldwide. There are the sorption, adsorption, and kinetics of isotherm phenomena for single-sorbate equilibrium, multisorbate equilibrium, and etc., that is, the multicomponent Langmuir models with considering electrostatic binding and the effect of $\mathrm{pH}[17]$.

In recent times, many researchers are involving the removal of heavy metal ions. Many technological ideas are involved in the removal mechanism by functional groups, surface charge, surface area, absorption, adsorption phenomena, etc. [18-22]. In this work, maghemite and magnetite nanoparticles are synthesized and are used for copper and chromium removal from wastewater. In this work, the authors adopted the adsorption phenomena and the effluents removal of pollutant of hexavalent chromium and divalent copper ions. The analysis used XRD, FTIR, SEM, EDS, and some physicochemical methods.

\section{EXPERIMENTAL}

Materials. In this study, all the following annular grade chemicals were used: ferrous chloride, ferric chloride, ethanol, ammonium hydroxide, hydrochloric acid, sodium hydroxide, potassium dichromate, cupric sulphate, and nitric acid [23].

Preparation. At first, 1:2 ratios of ferrous chloride and ferric chloride were mixed in $50 \mathrm{ml}$ of deionized water using a magnetic stirrer. This mixture was simultaneously heated at a temperature of $80^{\circ} \mathrm{C} .1 .5 \mathrm{M}$ ammonium hydroxide was added dropwise to the above mixture till the $\mathrm{pH}$ of the solution reached 11, and then the solution was allowed to cool and attain room temperature. This solution was then centrifuged to remove unwanted substances and was dried over night at a temperature of $60^{\circ} \mathrm{C}$ to obtain black-colored magnetite nanoparticles. These magnetite nanoparticles were further heated at a temperature of $250^{\circ} \mathrm{C}$ for 4 hours to obtain reddish brown maghemite nanoparticles.

Reaction: $\mathrm{FeCl}_{2}+2 \mathrm{FeCl}_{3}+8 \mathrm{NH}_{4} \mathrm{OH} \rightarrow \mathrm{Fe}_{3} \mathrm{O}_{4}+{ }_{4} \mathrm{H}_{2} \mathrm{O}+8 \mathrm{NH}_{4} \mathrm{Cl}$

Magnetite

Maghemite

$$
\mathrm{Fe}_{3} \mathrm{O}_{4} \rightarrow \mathrm{Fe}_{2} \mathrm{O}_{3}+\mathrm{Fe} \phi
$$

The above procedure was followed by different ratios of ferrous and ferric chloride precursors as ratio of 1:2, 0.1:0.2, and 0.01:0.02 as presented in Table S1. From Table S1, at ratio 1:2, though the weight of the produced particles was high, the size of the nanoparticles was large. At ratio 0.01:0.02, the size of the nanoparticles was small, but the weight of the produced particles was low, so the ratio 0.1:0.2 was selected for the synthesis of the nanoparticles. At this ratio, though the particle was high compared to 0.01:0.02, the weight was higher; this was moderate, neither too high nor too low. For adsorption isotherm analysis, the adsorbent and adsorbate play a main role; that is, the substance whose molecules get adsorbed on the surface of adsorbent is known as adsorbent. In general, it takes the following form:

$$
\mathrm{A}+\mathrm{B} \Leftrightarrow \mathrm{AB}
$$

where $\mathrm{A}$ - adsorbate, $\mathrm{B}$ - adsorbent, and $\mathrm{AB}$ are adsorption, respectively. The forward case is adsorption, and the reverse case is desorption. 


\section{RESULTS AND DISCUSSIONS}

X-ray diffraction analysis. For the interpretation of the X-ray diffraction analysis, and compared with the JCPDS reference code 96-900-6317 of maghemite and standard magnetite nanoparticle of JCPDS code 01-086-1358, the crystalline parameters are shown in Table 1, and their patterns are in Table S2. From this, we inferred that the synthesized particles matched with the standard maghemite and gave a score of 71 , and the magnetite has a score of 82 [24].

Table 1. XRD data for maghemite and magnetite.

\begin{tabular}{|c|c|c|c|c|}
\hline Pos. [ $\left.{ }^{\circ} 2 \mathrm{Th}.\right]$ & $\begin{array}{l}\text { Height } \\
\text { [counts] }\end{array}$ & $\begin{array}{c}\text { FWHM Left } \\
{\left[{ }^{\circ} 2 \mathrm{Th} .\right]}\end{array}$ & d-spacing $[\AA ̊]$ & Rel. Int. [\%] \\
\hline \multicolumn{5}{|c|}{ Maghemite } \\
\hline 11.2746 & 10.88 & 2.3616 & 7.84824 & 22.99 \\
\hline 30.6679 & 14.43 & 0.5904 & 2.91531 & 30.49 \\
\hline 36.0250 & 47.33 & 0.3936 & 2.49313 & 100.00 \\
\hline 44.0166 & 5.31 & 1.1808 & 2.05725 & 11.22 \\
\hline 57.9103 & 12.26 & 0.5904 & 1.59244 & 25.91 \\
\hline 63.3896 & 19.84 & 0.7872 & 1.46735 & 41.91 \\
\hline \multicolumn{5}{|c|}{ Magnetite } \\
\hline 30.5358 & 25.84 & 0.3936 & 2.92762 & 18.68 \\
\hline 35.9868 & 138.35 & 0.2952 & 2.49569 & 100.00 \\
\hline 43.5981 & 27.02 & 0.3936 & 2.07602 & 19.53 \\
\hline 53.9592 & 14.92 & 0.5904 & 1.69932 & 10.79 \\
\hline 57.4921 & 36.53 & 0.5904 & 1.60302 & 26.40 \\
\hline 63.0193 & 58.28 & 0.3936 & 1.47508 & 42.13 \\
\hline 74.4297 & 9.23 & 0.5904 & 1.27469 & 6.67 \\
\hline
\end{tabular}



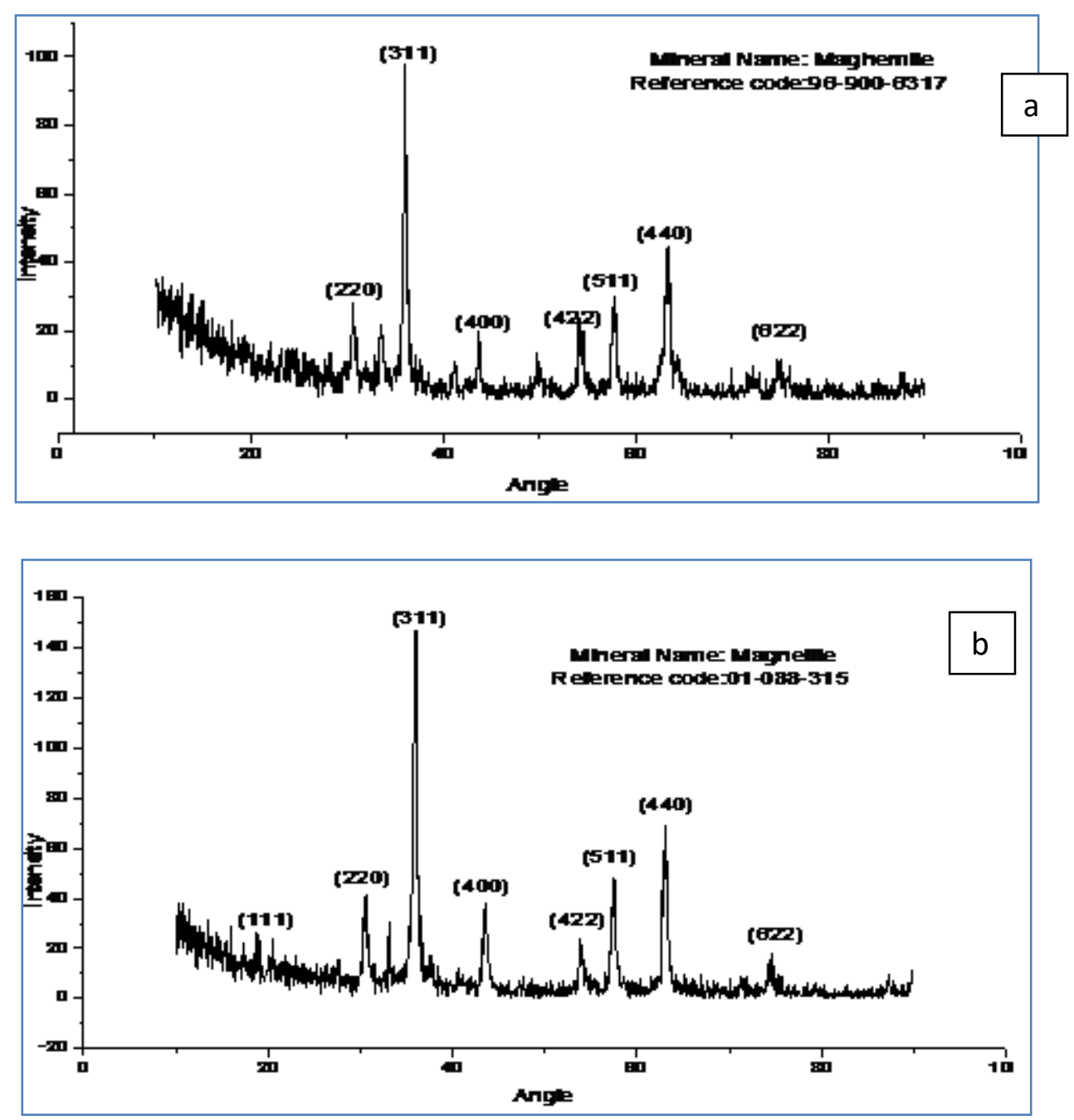

Figure 1. XRD spectra of (a) maghemite and (b) magnetite.

Crystal size determination. This was done using Sherwood equation, according to which the crystal size $=$ $(0.9 \lambda / \beta \cos \theta)$, where $\lambda$ - wavelength of the radiation $=0.544 \mathrm{~nm}, \beta$-full width half maximum value of the peak in radians (for $100 \%$ intensity) $=6.8696 \times 10^{-3}$ radians.

$$
\Theta=\frac{2 \theta}{2}=18.0125
$$

Therefore, the crystal size is $21.21 \mathrm{~nm}$ for maghemite and $28.21 \mathrm{~nm}$ for magnetite.

SEM analysis. Figures 2(a) to (c) show the SEM images of maghemite nanoparticles. We can see that the particles were crystalline, and the size of the particles was found to be in the range of $25-80 \mathrm{~nm}$. And from the SEM images (Fig. 2 (d-f)) showing the magnetite nanoparticle, we can infer that the particles were in the range from 25 to $100 \mathrm{~nm}$ and crystalline in nature [24, 25]. 

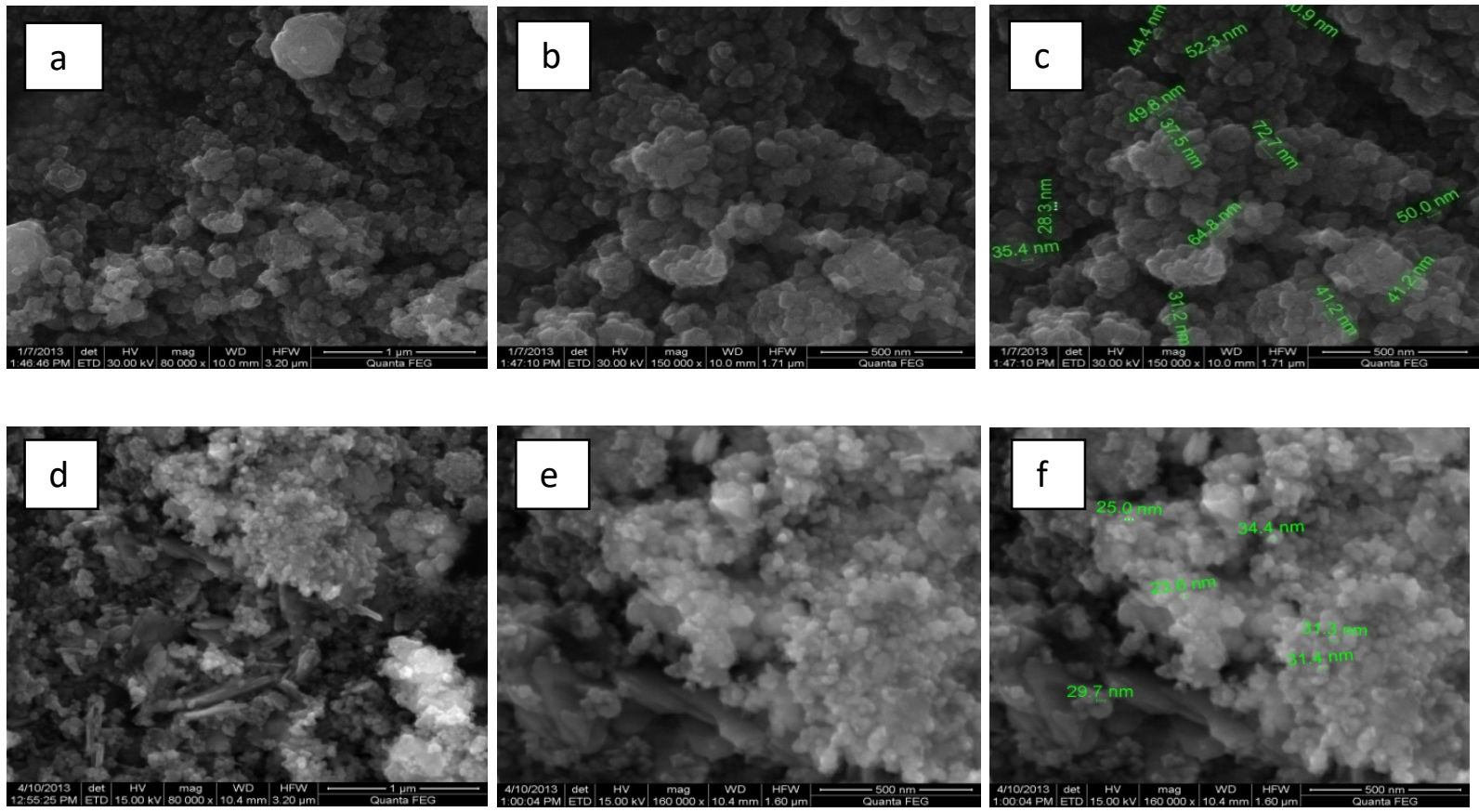

Figure 2. SEM images of maghemite at (a) $1 \mu \mathrm{m}$, (b) 500nm, and (c) $500 \mathrm{~nm}$ and magnetite at (d) $1 \mu \mathrm{m}$, (e) $500 \mathrm{~nm}$, and (f) $500 \mathrm{~nm}$.

EDS analysis. This analysis confirmed the presence of iron and oxygen elements. Figures S1(a) and (b) show the EDS spectrum of maghemite and magnetite nanoparticles. They show the presence of $\mathrm{Fe}$ and $\mathrm{O}$ ions. In addition, the presence of impurities such as chlorine and carbon can be observed, and ferrous chloride precursor and ethanol were used during synthesis [25].

FTIR analysis. The characteristic bands from figs. 4 (a) and (b) for maghemite and magnetite particles were checked, and they are given in Table S3.
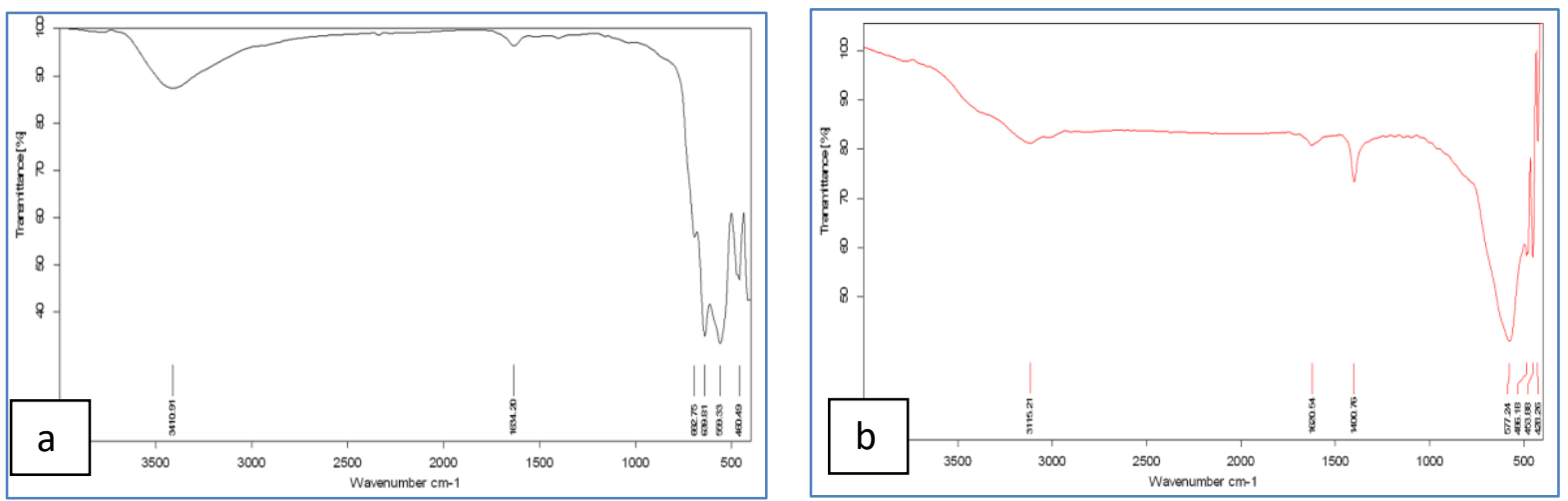

Figure 3. FTIR spectra of (a) maghemite and (b) magnetite. 
From Fig. 3(a), the sharp peaks at the bands $682.75 \mathrm{~cm}^{-1}, 639.81 \mathrm{~cm}^{-1}, 589.33 \mathrm{~cm}^{-1}$, and $460.49 \mathrm{~cm}^{-1} \mathrm{can}_{\text {be }}$ observed, and these values approximately match the characteristic bands of the pure maghemite obtained from the literature, thus indicating the formation of maghemite phase. The band around $639.81 \mathrm{~cm}^{-1}$ is a characteristic band of maghemite, which helps us distinguish it from maghemite phase [27].

Magnetite nanoparticles. The characteristic bands for magnetite phase were obtained from Fig. 4(b), and the characteristic bands were seen at $3115.21 \mathrm{~cm}-1,1620.54 \mathrm{~cm}-1,1400.76 \mathrm{~cm}-1,577.24 \mathrm{~cm}-1,486.18 \mathrm{~cm}-1,453.88 \mathrm{~cm}-$ 1 , and $428.26 \mathrm{~cm}-1$, which matched quite well with the characteristic bands of magnetite nanoparticles. The peak at 577.24 is attributed to the vibration of iron oxygen bond of magnetite, thus indicating the formation of magnetite phase $[27,28]$.

\section{Application of Nanoparticles for Removal of Copper and Chromium Ions}

Magemite nanoparticles. The adsorption experiments were conducted to determine the effect of different parameters such as $\mathrm{pH}$, temperature, contact time, and dosoge. A stock solution of $100 \mathrm{ppm}$ was made using potassium dichromate and cupric sulphate in deionized water.

Effect of pH. Fig. 4.a shows the effect of $\mathrm{pH}$ on the maghemite nanoparticles, and $50 \mathrm{ml}$ of 8 ppm potassium dichromate and cupric sulphate was mixed with 0.1 grams of maghemite nanoparticles using a shaker at room temperature for a contact time of 1 hour. Then, the concentration of chromium and copper in the solutions was checked using Atomic Absorption Spectrophotometer [29].
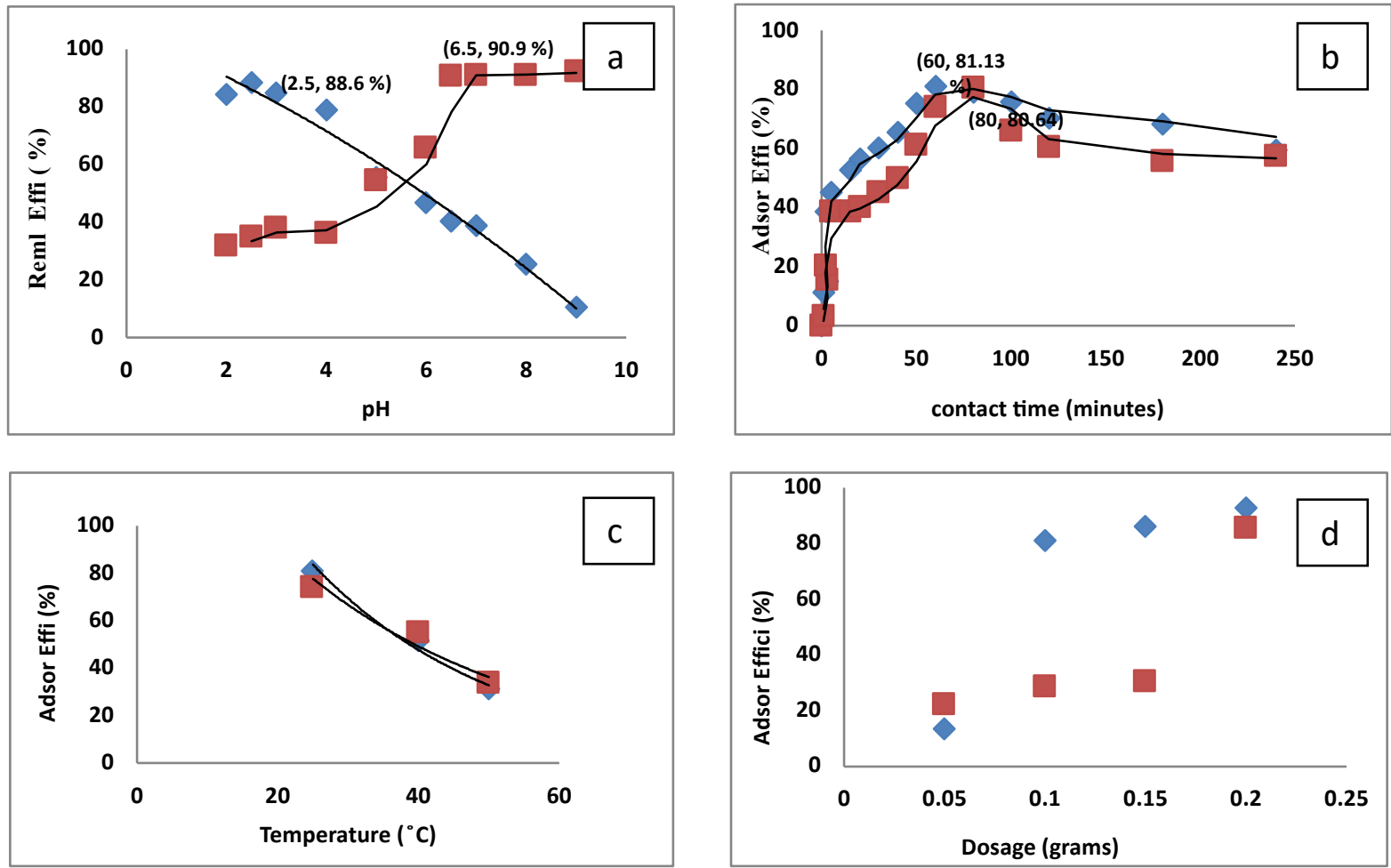

Figure 4. Effect of removal efficiency (Y- Fe2O3) vs (a) pH, (b) contact time, (c) temperature, and (d) dosage $(\diamond-\mathrm{Cr}, \quad \square-\mathrm{Cu})$. 
From Fig. 4 (a), we can see that the maximum chromium was removed at lower $\mathrm{pH}$, and maximum copper was removed at highly basic $\mathrm{pH}$. The removal of metal ions with respect to $\mathrm{pH}$ is based on surface phenomena by hydroxyl groups. The change of surface charge is neutral at zero point charge (zpc) is 6.3. It is positive below the zpc and is favored to anion adsorption through electrostatic attraction. Above zpc, the surface is negatively charged, and so, cation adsorption takes place. Increasing $\mathrm{pH}, \mathrm{Cr}$ ion get decreased due to $\mathrm{OH}^{-}$ions. At the same time, the electrostatic repulsion between the $\mathrm{Cr}$ ion and negatively charged nanoparticles can be released by adsorption of chromium ions $[20,29]$.

In this case, the charge on surface is due to coulombic repulsion of metals ions. The dependance of pzc with $\mathrm{pH}$ of copper is because there is an exchange of $\mathrm{Cr}^{2+}$ and $\mathrm{H}^{+}$ions [20,29]. Thus, a pH of 2.5 and 6.5 was suitable for the removal of chromium and copper metal ions.

Effect of contact time. From Fig. 4(b), it can be inferred that the removal efficiency increased with the increase in contact time; then, it slightly decreased, indicating equilibrium time of 60 minutes and 80 minutes for chromium and copper ions, respectively [30].

Effect of temperature. $50 \mathrm{ml}$ of copper and chromium metal solutions was mixed with 0.1 grams of maghemite nanoparticles at their suitable $\mathrm{pH}$ at temperatures $25^{\circ} \mathrm{C}, 40^{\circ} \mathrm{C}$, and $50^{\circ} \mathrm{C}$. Fig. $4(\mathrm{c})$ shows that the maximum removal of heavy metals was possible only at room temperature. The adsorption of heavy metals is caused due to the electrostatic attraction between the nanoparticles and metal ions, which is not favored at higher temperature.

Effect of dosage. $0.05,0.10,0.15$, and 0.20 grams of nanoparticles were mixed with $50 \mathrm{ml}$ of the stock solution using a orbital shaker as shown in fig. 5(d), and the concentration of heavy metals was checked using AAS [31]. It can be seen that the rate of heavy metal removal increased with the increase in the amount of nanoparticles, which means increasing the adsorption surface.
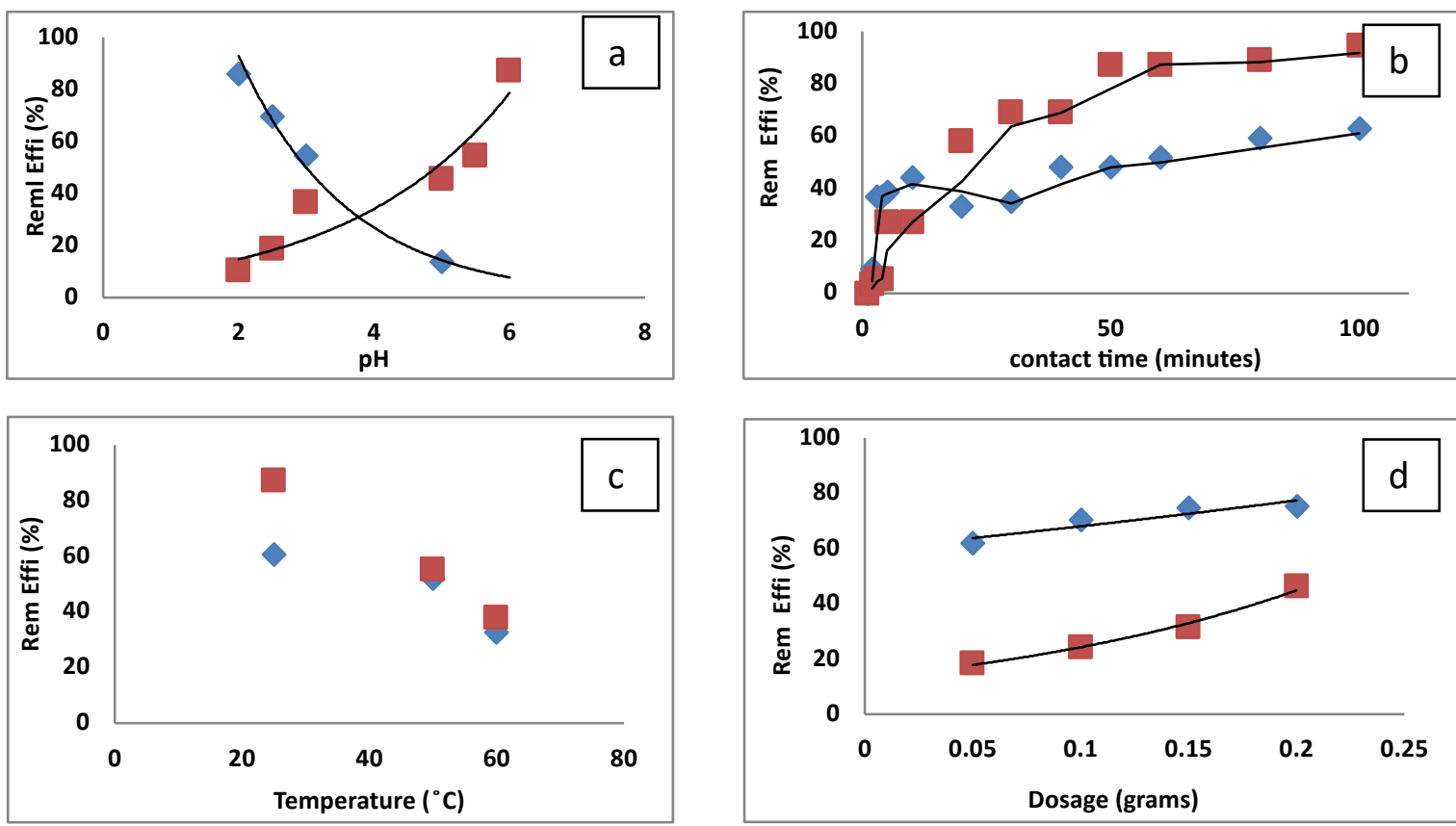

Figure 5. Effect of removal efficiency $\left(\gamma-\mathrm{Fe}_{3} \mathrm{O} 4\right)$ vs (a) $\mathrm{pH}$, (b) contact time, (c) temperature, and (d) dosage $(\diamond-\mathrm{Cr}, \square-\mathrm{Cu})$. 
Magnetite nanoparticles. In order to determine the effect of parameters, the same procedure and conditions were followed, which were maintained for maghemite nanoparticles.

Effect of pH. $50 \mathrm{ml}$ of $8 \mathrm{ppm}$, potassium dichromate, and cupric sulphate solutions was mixed with 0.1 grams of nanoparticles, at a pH range of 2 to 6 using an orbital shaker. From fig. 5(a), it can be shown that the removal of chromium is maximum at lower $\mathrm{pH}$, mayby due to the formation of $\mathrm{OH}$-ions, which compete with the chromium species for the adsorption sites on the magnetite nanoparticles [32].

$$
\mathrm{sH}_{2} \mathrm{O}+\mathrm{q} \equiv \mathrm{FeOH}+\mathrm{rCu}^{2+} \leftrightarrow(\equiv \mathrm{FeO}) \mathrm{qCu}_{\mathrm{r}}\left((\mathrm{OH})^{(2-\mathrm{q}-\mathrm{s})}\right)_{\mathrm{s}}+(\mathrm{s}+\mathrm{q})^{\mathrm{H}+}
$$

where $\mathrm{s}, \mathrm{q}$, and $\mathrm{r}$ indicate the stoichiometric coefficients. The increase in $\mathrm{pH}$ helps increase more numbers of sites influencing higher $\mathrm{Cu}^{2+}$ gets absorbed as magnetite.

Effect of contact time. $100 \mathrm{ml}$ of potassium dichromate and cupric sulphate from stock solution was mixed with 0.1 grams of magnetite nanoparticles using an orbital shaker. Samples were collected at specific intervals of time, and the metal concentration was measured using atomic absorption spectroscopy. Fig. 5(b) shows that the removal rate for both metals increased with the increase in contact time [33].

Effect of temperature. $50 \mathrm{ml}$ of stock solution was mixed with 0.1 grams of magnetite nanoparticles at $25^{\circ} \mathrm{C}$, $50^{\circ} \mathrm{C}$, and $60^{\circ} \mathrm{C}$ in an incubator shaker at their suitable pH. From the graph (Fig. 5(c)), it can be seen that the maximum removal of both the metals was possible at room temperature, indicating that the maximum physical adsorption happened at room temperature [34]. The removal rate increased with the increase in dosage, as the adsorption sites increased were depicted in Fig. 5(d) [35].

\section{Analysis of Adsorbed Nanoparticles}

FTIR analysis. The characteristic bands for chromium are seen at wavenumbers $3500 \mathrm{~cm}^{-1}, 1100 \mathrm{~cm}^{-1}, 609 \mathrm{~cm}^{-}$ 1, $556 \mathrm{~cm}^{-1}$, and $443 \mathrm{~cm}^{-1}$. Afterwards, we can see the FTIR graphs of maghemite and magnetite nanoparticles. We can see the peaks at $928 \mathrm{~cm}^{-1}, 598.67 \mathrm{~cm}^{-1}$, and $476.71 \mathrm{~cm}^{-1}$, indicating the adsorption of chromium ions on the surface of maghemite nanoparticles. The peaks at $1622.64 \mathrm{~cm}^{-1}, 571.72 \mathrm{~cm}^{-1}, 478.17 \mathrm{~cm}^{-1}$, and $426.67 \mathrm{~cm}^{-1}$ indicate the chromium adsorption on magnetite nanoparticles (Figs. 6(a) and (b)) [28, 34].

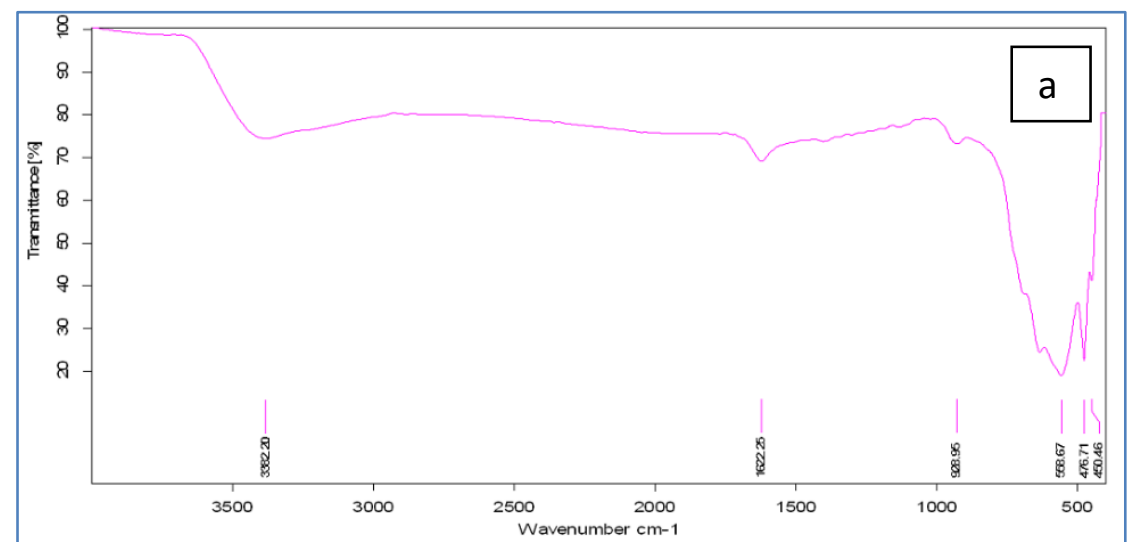




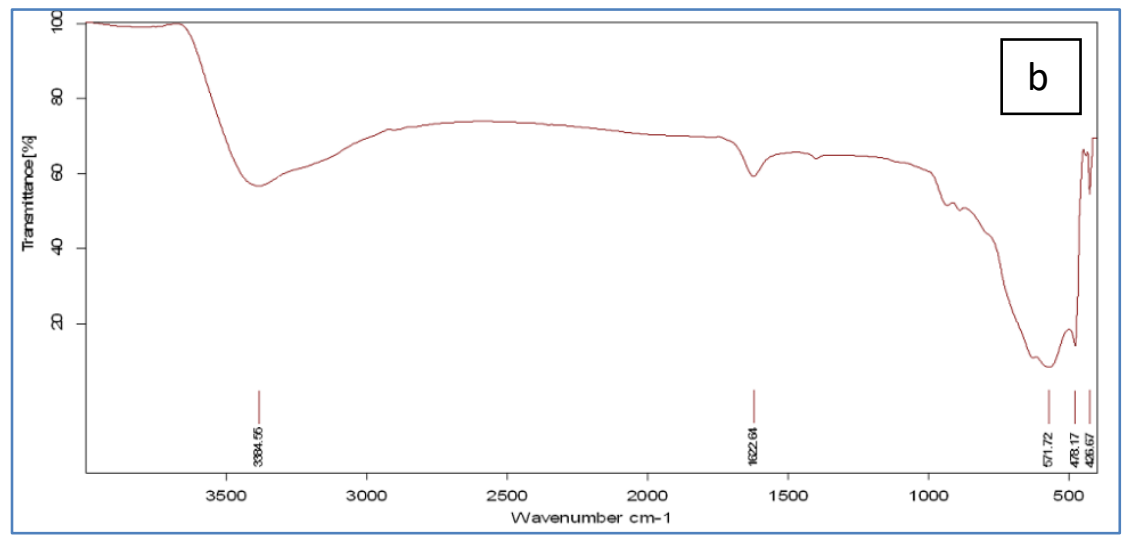

The characteristic bands for copper ions are at $1093 \mathrm{~cm}-1$ and $465 \mathrm{~cm}-1$. Fig. 8(a) shows the graph of FTIR spectra for maghemite nanoparticles, and we see the peaks at $571.72 \mathrm{~cm}-1,478.17 \mathrm{~cm}-1$, and $426.67 \mathrm{~cm}-1$, which can be considered for copper metal ion adsorption. For magnetite, we have peaks at $587.23 \mathrm{~cm}-1,476.97 \mathrm{~cm}-1$, and $425.42 \mathrm{~cm}-1$, which also indicate that the copper adsorption on magnetite nanoparticles is observed in Figs. 6(c) and (d) [35].
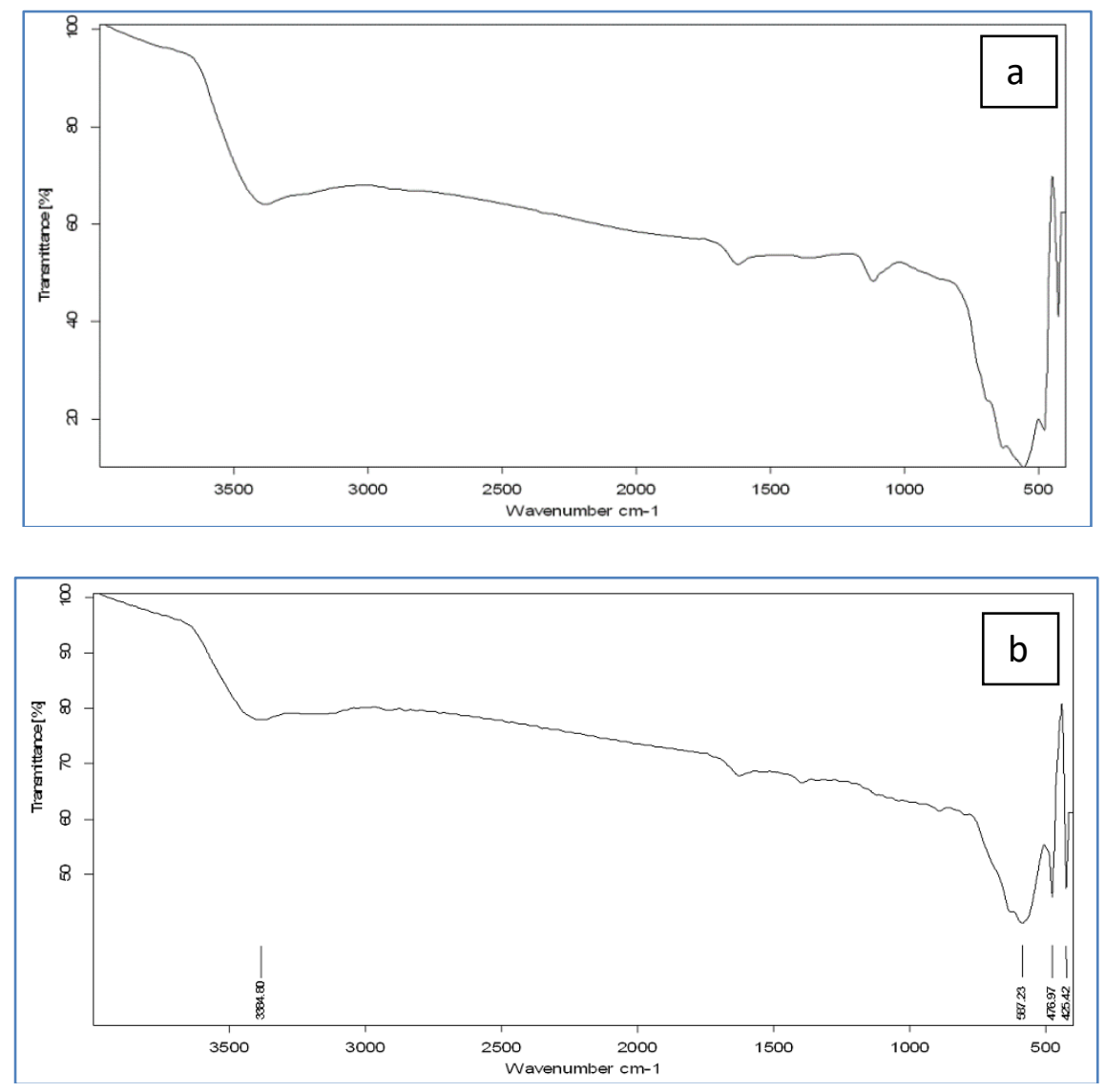

Figure 6. FTIR spectra of Chromium adsorbed (a) maghemite and (b) magnetite manoparticles and copper adsorbed (c) maghemite and (d) magnetite nanoparticles. 
Energy dispersive spectrum of chromium adsorbed nanoparticles. These results prove the adsorption of chromium ions on maghemite and magnetite nanoparticles (Figure S2).

Desorption studies. Maghemite and magnetite nanoparticles were regenerated using $0.2 \mathrm{M} \mathrm{HCl}$ and $0.01 \mathrm{M}$ $\mathrm{NaOH}$ effluent for desorption of copper and chromium metal ions. 0.1 grams of chromium adsorbed nanoparticles was mixed with $20 \mathrm{ml} 0.01 \mathrm{M} \mathrm{NaOH}$, which is a base; this caused the desorption of chromium species due to electrostatic repulsion as the surface charge of nanoparticles was negative because the $\mathrm{pH}$ was above zero point of charge. Similarly, copper adsorbed nanoparticles were regenerated using $0.2 \mathrm{M} \mathrm{HCl}$; due to the decrease in $\mathrm{pH}$, the nanoparticle surface charge was below zero point of charge, thus causing electrostatic repulsion between copper ions and nanoparticles $[36,37]$. These regenerated particles were then used for removal of chromium and copper metal ions from wastewater as shown in Table S4.

Adsorption isotherm. Langmuir isotherm was found to be best fit for both maghemite and magnetite nanoparticles. The metal removal levels for isotherm plots curve were determined using Langmuir model. The isotherm equation relates with adsorbent surface with the number of binding sites. They are modeled according to following equation:

$$
\frac{C_{e}}{Q_{e}}=\left(\frac{1}{b}\right) Q_{m}+\frac{C_{e}}{Q_{m}}
$$

where $\mathrm{b}$ and $\mathrm{Q}_{\mathrm{m}}$ are the Langmuir constant and maximum capacity of adsorption, and the values are obtained through $\mathrm{Ce} / \mathrm{Q}$ vs Ce values.

The important factor determines the adsorption phenomena; if $r>$ is unfavored, $r=1$ is linear, $r<1$ is favored, and $r=0$ is completely irreversible (27), and this $r$-value is calculated through the following expression:

$$
r=\frac{1}{\left(1+b C_{0}\right)}
$$

Here, $\mathrm{C}_{0}$-initial concentration $(8 \mathrm{ppm}), \mathrm{r}$ - lies in the range $0-1$ that is favored to adsorption of chromium and copper as maghemite and magnetite nanoparticles [25]. The Langmuir model is among those accepted (isothermal model for single solutions). The steep initial slope of sorption isotherm indicates desirable high affinity for absorbance phenomena, thus, for good sorbents having high and steep initial sorption isotherm slope [38].

Adsorption isotherm for chromium ions. From Fig. 7(a), the value of $\mathrm{Q}_{\mathrm{m}}$ and $\mathrm{b}$ was $6.77 \mathrm{mg} \mathrm{g}^{-1}$ and $677 \mathrm{Lmg}^{-1}$. Separation factor ' $r$ ' value was between 0 and 1, indicating favorability of Langmuir isotherm. And from fig. 7(b), the value of $Q_{m}$ and $b$ was $7.46 \mathrm{mgg}^{-1}$ and $466.41 \mathrm{Lmg}^{-1}$. Separation factor ' $r$ ' value was between 0 and 1 , indicating favorability of Langmuir isotherm [39]. 

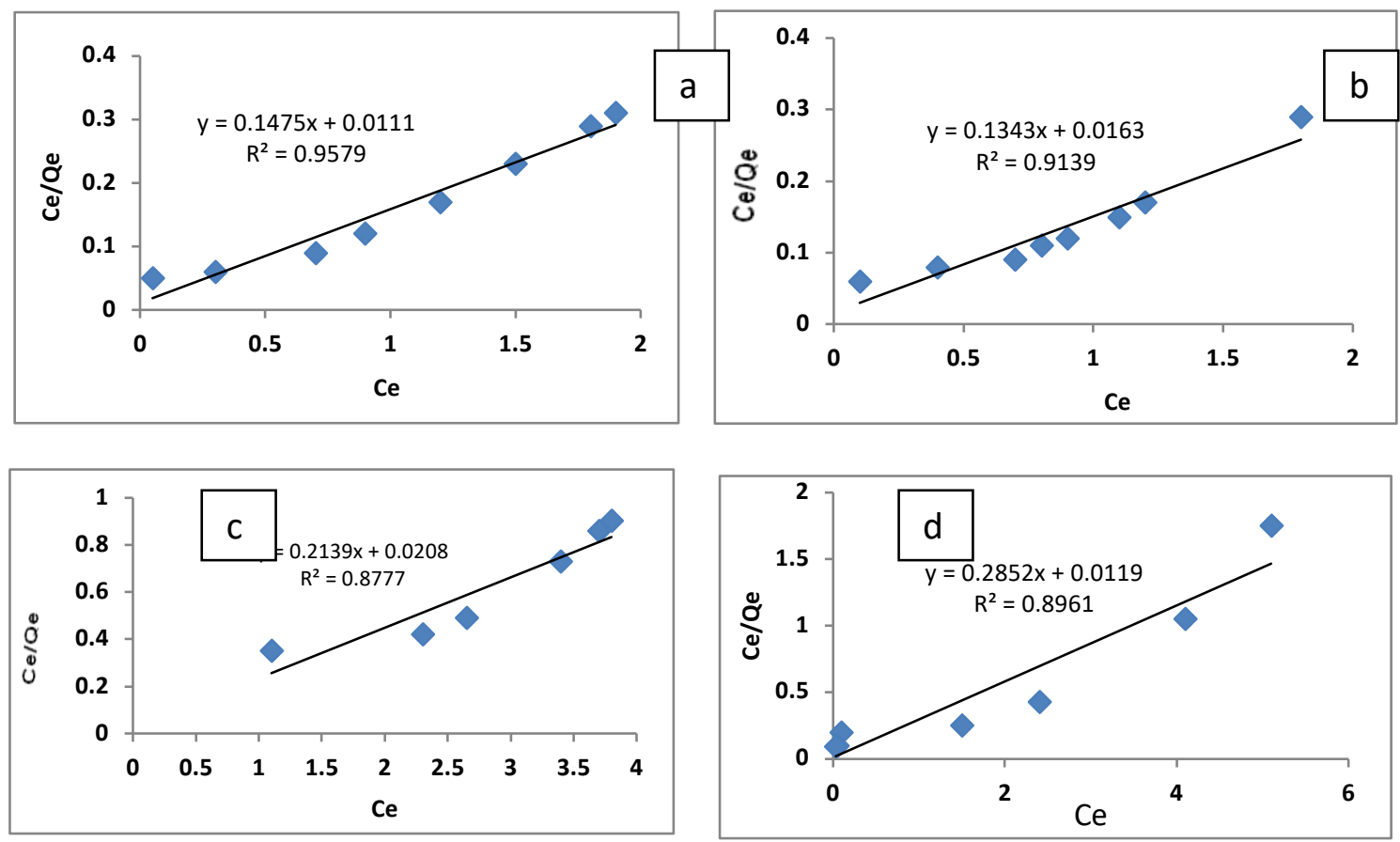

Figure 7. Langmuir isotherm for chromium removal (a) maghemite, (b) magnetite and copper removal, (c) maghemite, and (b) magnetite.

Adsorption isotherm for copper ions. The value of $\mathrm{Q}_{\mathrm{m}}$ and $\mathrm{b}$ was $4.675 \mathrm{mg}^{-1}$ and $677 \mathrm{Lmg}^{-1}$. Separation factor ' $r$ ' value was between 0 and 1, indicating favorability of Langmuir isotherm as shown in Fig. 7(c). And from Fig. $7(\mathrm{~d})$, the value of $\mathrm{Q}_{\mathrm{m}}$ and $\mathrm{b}$ was $3.5 \mathrm{mg}^{-1}$ and $318.75 \mathrm{Lmg}^{-1}$. Separation factor ' $r$ ' value was between 0 and 1 , indicating favorability of Langmuir isotherm [40]. The similar and best results reported through Langmuir isotherm model with $\left(\mathrm{R}^{2}=0.999\right)$ are better than those reported by Freundlich model $\left(\mathrm{R}^{2}=0.918\right)$ for the removal of Zinc (II) [41], cadmium $\left(\mathrm{Cd}^{2+}\right)$, and lead $\left(\mathrm{Pb}^{2+}\right)$ [42] and were found to be highest for Freundlich model, 0.9946 and 0.997 for Langmuir model for Cd (II) and Zn (II) biosorption, respectively [43]. This indicates that the chosen Langmuir isotherm is good for fit and analysis.

\section{CONCLUSIONS}

The maghemite $(25 \mathrm{~nm}-80 \mathrm{~nm})$ and magnetite $(25 \mathrm{~nm}-100 \mathrm{~nm})$ nanoparticles were synthesized, which showed more percentage metal ions removal. Crystallite size of $21.21 \mathrm{~nm}$ for maghemite and $28.21 \mathrm{~nm}$ for magnetite were confirmed through XRD spectra. The presence of Fe and $\mathrm{O}$ is confirmed by the EDS analysis. Chromium adsorption on magnetite is evident from the peaks at $1622.6 \mathrm{~cm}-1,571.72 \mathrm{~cm}-1,478.17 \mathrm{~cm}-1$, and $426.67 \mathrm{~cm}-1$, and copper adsorption at peaks at $587.23 \mathrm{~cm}-1,476 \mathrm{~cm}-1$, and $425.42 \mathrm{~cm}-1$ is confirmed by the FTIR analysis. The band around $639.81 \mathrm{~cm}^{-1}$ is a characteristic band of maghemite. Adsorption depends on the optimum conditions of parameters such as $\mathrm{pH}$ (2.5 and 6.5), contact time (60 and 80) minutes, and dosages at room temperature for chromium and copper that were concluded with removal efficiency (92\%). It was observed that the removal of chromium ions was high (41.66\% and 33.33\%) at acidic $\mathrm{pH}$, and the removal of copper ions was high (30.56 and 25.90) at basic $\mathrm{pH}$ from desorption analysis, thus proving that these nanoparticles can be used for removal of both cation and anion heavy 
metal ions. The data's fit in well for Langmuir adsorption isotherm and desorption studies showed that these particles can be reused for water treatment.

\section{Conflicts of Interest}

The authors have no conflicts of interest.

S. Nithiyanantham (corresponding author).

\section{REFERENCES}

C. Kumar, Magnetic Nanomaterials (Weinheim: Wiley-VCH Verlag GmbH \& Co.) 648, (2009).

R. Mahalakshmi, K. Preethi, D. Kalaiselvi, M. Manjuladevi, K. Karthik, R. Marimuthu, Rasayan J Chem, 12 (1), 245 (2019).

V. K.Gupta, R. Jain, A. Mittal, T. A.Saleh, A.Nayak, S. Agarwal, Materials Science and Engineering C; 32(1), 12 (2012).

T. A. Saleh, V.K. Gupta, Environm Sci Pollu Resear, 19(4), 1224 (2012).

J. Hu, I. Lo, G. Chen, Separation and Purification Technology, 56, 249 (2007).

V.K.Gupta, S. Agarwal, T.A. Saleh, J Hazard Mats., 185(1), 17 (2011).

V. K. Gupta, I. Ali, T. A. Saleh, A. Nayak, S. Agarwal, RSC Advances ; 2(16), 6380 (2012).

A. Mittal, J. Mittal, A. Malviya, V.K. Gupta, J Coll Interface Sci, 344(2), 497 (2010).

R.Saravanan, E. Sacari, F.Gracia, M. MansoobKhan, E.Mosquera, V. K.Gupta, J Mol Liqds, 221, 1029 (2016).

R. Saravanan, M. Mansoob Khan, F. Gracia, J. Qin, V. K. Gupta, S. Arumainathan, Scientific Reports, 6, 31641 (2016).

X.Z. Wang, P. C Dou, Y. Ding, P. Xu, Biores Tech, 100, 2301 (2009).

R. Saravanan, M. Mansoob Khan, V. K. Gupta, E. Mosquera, F. Gracia, V. Narayanan, A. Stephen, RSC Advances, 5, 34645 (2015).

V.K. Gupta, T.A,. Saleh, Environ Sci Poll Res, 20 (5), 2828 (2013).

P. Somasundaram, Encyclopedia of Surface and Colloid Science, 2004 Update Supplement 5,1,CRC Press, Pages, 704, 2004.

R. Saravanan, M. Mansoob Khan, V.K. Gupta, E. Mosquera, F. Gracia, V. Narayanan, A. Stephen , J Coll Inter Sci, 452, 126 (2015).M. Devaraj, R.Saravanan, R. K. Deivasigamani, V. K. Gupta, F.Gracia, S. Jayadevan, J Mol Liqds, 221, 930 (2016).

J. Wang, C. Chen, Biotech Advan, 24(5), 427 (2006).

C.I. Covaliu, G. Georgescu, I. Jitaru, J. Neamtu, T. Malaeru, O. Oprea and E. Patroi, Revista Chimie, 60 (12) 1254 (2009).

A. Predescu, A. Nicolae, Basic Sci Bull Seri - B, 74(1), 1454, (2012).20. M. Manjuladevi, R. Anitha, S. Manonmani, Appl Wat Sci, 8, 36 (2018).

R.Saravanan, F.Gracia, K. Mohammad Mansoob, V.Poornima, V. K. Gupta, V.Narayanan, A.Stephen, J Mol Liqds, 209, 374 (2015). 
R.Saravanan, V. K. Gupta, E. Mosquera, F.Gracia, V.Narayanan, A.Stephen, J Saudi Chem Soc., 19(5), 521 (2015).

A. Predescu, E. Matei, A. Predescu, A. Berbecaru, Removal efficiency on magnetite (Fe3O4) of some multicomponent systems present in synthetic aqueous solutions, Recent Researches in Communications, Electronics, Signal Processing and Automatic Control.

E Matei, A Predescu, E Vasileand A Predescu, J Phys. Conf. Se, 304, 012022 (2011).

H. Jing, C. Guohua, M.C. Irene, M.Lo, ASCE J Env Engg, 132 (7), 709 (2006).

W. Xue Song, Z. Lei, Hai, L. Lu, Desalination, 276, 154 (2011).

S. Laurent, D. Forge, M. Port, A.Roch, C. Robic L.Vander Elst, R.N. Muller, Chem. Rev 108, 2064 (2008).

J. Wenjun, P. Miguel, D. Dionysios, M. H. Entezari, T. Dimitra, K. O. Shea, Chem Engg Jour, 222, 527 (2013).

A. Roy, J. Bhattacharya, Chem. Eng. J. 211, 493 (2012).

E. Darezereshki, M. Ranjbar, F. Bakhtiari, J. Alloys Comp. 502, 257 (2010).

P. Yuan, D. Liu, M. Fan, D. Yang, R. Zhu, F. Ge, J. Zhu, H. He, J. Hazard. Mater. 173, 614 (2010).

B.H. Hameed, J.M. Salman, A.L. Ahmad, J. Hazard. Mater. 163, 121 (2008).

C.S. Uyguner, M. Bekbolet, Appl. Catal. B, 49, 267 (2004).

J.D. Hu, Y. Zevi, X. M. Kou, J. Xiao, X.J. Wang, Y. Jin, Sci. Total. Environ. 408, 3477 (2010). M. Owlad, M.K. Aroua, W.A.W. Daud, S. Baroutian, Water Air Soil Pollut. 200. 59 (2009).

S.S. Banerjee, D. Chen, J. Hazard. Mater. 147, 792 (2007).

J. Hu, I.M.C. Lo, G. Chen, Sep. Purif. Technol. 56, 249 (2007).

J. wang, C. Chen, Biotechny Advan, 27, 195 (2009).

J. Hu, I.M.C. Lo, G. Chen, Water Sci. Technol. 50, 139 (2004).

C.T. Yavuz, J.T. Mayo, W.W. Yu, A. Prakash, J.C. Falkner, S. Yean, L. Cong, H.J.Shipley, A. M.Kan, D. Tomson, V. Natelson, L. Colvin, Science, 314(5801), 964 (2006).

C. Yang, J. Wang, M. Le, G. Xie, G. Zeng, S. Luo, J Environl Sci, 22(5), 675 (2010).

Y. Huang, C. Yang, Z. Sun, G. Zeng, H. He, RSC Advances, 5(15), 11475 2015).

B. Nagy, C. Ma nzatu, A. Maicaneanu, C. Indolean, B.Tudoran Lucian, C. Majdik, Arab J Chem. 10, S3569 (2017). 